\title{
Computed tomographic image comparison between mediastinal and lung windows provides possible prognostic information in patients with small peripheral lung adenocarcinoma
}

\author{
Boming Dong, $M D^{a, b}$ \\ Masami Sato, $\mathrm{MD}^{\mathrm{a}}$ \\ Motoyasu Sagawa, MD \\ Chiaki Endo, MD \\ Katsuo Usuda, MD \\ Akira Sakurada, MD \\ Shulin $\mathrm{Wu}, \mathrm{MD}^{\mathrm{a}}$ \\ Takeshi Oyaizu, MD \\ Itaru Ishida, MD \\ Masashi Handa, MD ${ }^{\mathrm{C}}$ \\ Takashi Kondo, MD
}

From the Department of Thoracic Surgery, Institute of Development, Aging and Cancer, Tohoku University, Sendai, Japan, ${ }^{a}$ the Department of Thoracic Surgery, The First Teaching Hospital affiliated with China Medical University, Shenyang, China, ${ }^{\mathrm{b}}$ the Department of Surgery, Sendai Kosei Hospital, Sendai, Japan, ${ }^{\mathrm{c}}$ the Department of Endoscopy, Toyama Medical and Pharmaceutical University, Toyama, Japan, ${ }^{\mathrm{d}}$ and the Department of Thoracic Surgery, Kanazawa Medical University, Kanazawa, Japan. $^{\mathrm{e}}$

Received for publication Nov 5, 2001; revisions requested Feb 5, 2002; revisions received Feb 13, 2002; accepted for publication April 16, 2002.

Address for reprints: Masami Sato, MD, Department of Thoracic Surgery, Institute of Development, Aging and Cancer, Tohoku University, 4-1 Seiryo-machi, Aobaku, Sendai 980-8575, Japan (E-mail: m-sato@idac.tohoku.ac.jp).

J Thorac Cardiovasc Surg 2002;124: 1014-20

Copyright $\odot 2002$ by The American Association for Thoracic Surgery

$0022-5223 / 2002 \$ 35.00+0 \quad \mathbf{1 2 / 1 / 1 2 5 6 4 7}$

doi: $10.1067 / \mathrm{mtc} .2002 .125647$
Objectives: The purpose of this study was to determine whether the ratio of the area of the mediastinal computed tomographic image to that of the lung computed tomographic image can be a prognostic factor of small peripheral lung adenocarcinoma.

Methods: We studied the computed tomographic images of 143 patients with primary peripheral lung adenocarcinoma of $30 \mathrm{~mm}$ or less in maximum diameter. Two groups were categorized according to the tumor's ratio of the area of the mediastinal computed tomographic image to that of the lung computed tomographic image (tumor's area in the mediastinal computed tomographic image/tumor's area in lung computed tomographic image $\times 100 \%)$, both faint density-type $(<50 \%)$ and solid-type images $(\geq 50 \%)$. Clinical factors and prognoses of the 2 groups were analyzed.

Results: There were 58 patients with the solid-type tumor image and 85 patients with the faint density-type tumor image. The number of patients with tumor size of less than $20 \mathrm{~mm}$ in the faint density-type tumor group $(\mathrm{n}=30)$ was significantly higher than that in the solid-type tumor group $(\mathrm{n}=8, P=.008)$. The 5 -year survival of patients with faint density-type tumors was $74.1 \%$, whereas that in patients with solid-type tumors was $54.2 \%(P=.013)$. Furthermore, the survival curve of patients with the solid-type computed tomographic image combined with ground-glass opacity was similar to that of patients with the faint density-type image. Multivariate analysis revealed the prognostic influence of the ratio of the area of the mediastinal computed tomographic image to that of the lung computed tomographic image on survival $(P=.029$, relative risk $=0.48)$ and showed to be of second highest influence after the $\mathrm{N}$ factor.

Conclusions: It is suggested that the ratio of the area of the mediastinal computed tomographic image to that of the lung computed tomographic image can be a prognostic factor in patients with small peripheral lung adenocarcinoma. 


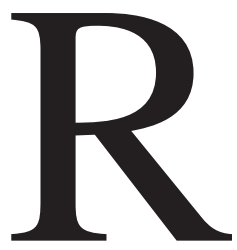

ecently, the number of patients with small peripheral lung cancer detected by means of computed tomographic (CT) scanning has been increasing. In Japan, CT mass screening has been started in many local municipalities. Most cancers detected by this method are small stage IA lung cancers in peripheral locations. In the United States the National Cancer Institute launched lung cancer screening with spiral CT scanning. Despite the small size of these tumors, some patients die of cancer recurrence, and thus it is important for us to know the biologic behavior of this type of cancer. Although many reports on the radiologic-pathologic correlation of small lung adenocarcinoma have been published, little clinical information on prognostic factors during the pretreatment state is available. ${ }^{1-5}$ Thus, new information relevant to prognosis is highly desired.

\section{Patients and Methods}

From January 1990 to December 1993, surgical resections were performed in 143 patients with primary peripheral lung adenocarcinoma with a maximum diameter of $30 \mathrm{~mm}$ or less. Of the 143 patients, $136(95.1 \%)$ underwent lobectomies, 5 (3.5\%) underwent pneumonectomies, and $2(1.4 \%)$ underwent segmental resections combined with systematic hilar and mediastinal node dissection. Informed consent was obtained from each patient before the op-

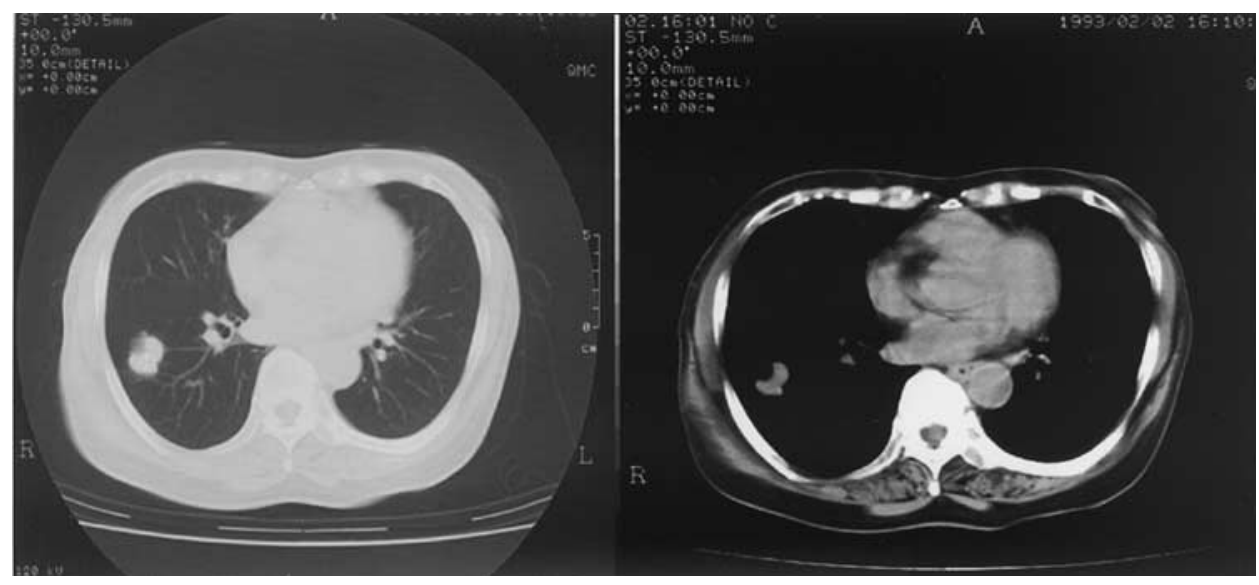

Figure 1. CT images of a patient with a solid-type tumor with GGO. The patient was a 70-year-old woman who underwent a right upper lobectomy combined with systematic nodal dissection. She remained alive for 7.6 years after the operation. The $\mathrm{CT} M / \mathrm{L}$ ratio was $60.5 \%$, and $\mathrm{GGO}$ was found around the solid-type tumor image. The tumor was proved to be a well-differentiated stage IIA (T1 N1 MO) papillary adenocarcinoma with a maximum tumor diameter of $25 \mathrm{~mm}$.

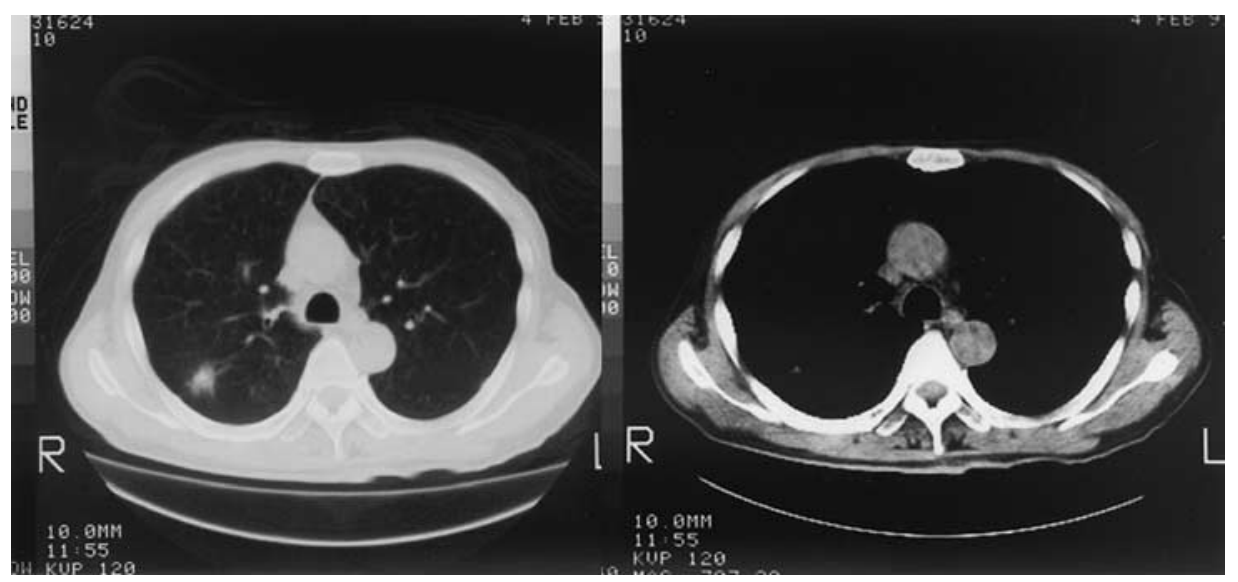

Figure 2. CT images of a patient with a faint density-type tumor with GG0. The patient was a 72-year-old man who underwent a right upper lobectomy combined with systematic nodal dissection. He was still alive as of the last follow-up ( 9.5 years). The CT M/L ratio was $3.9 \%$, and GGO was observed. The tumor was proved to be moderately differentiated stage IA (T1 NO MO) papillary adenocarcinoma with a maximum tumor diameter of $20 \mathrm{~mm}$. 


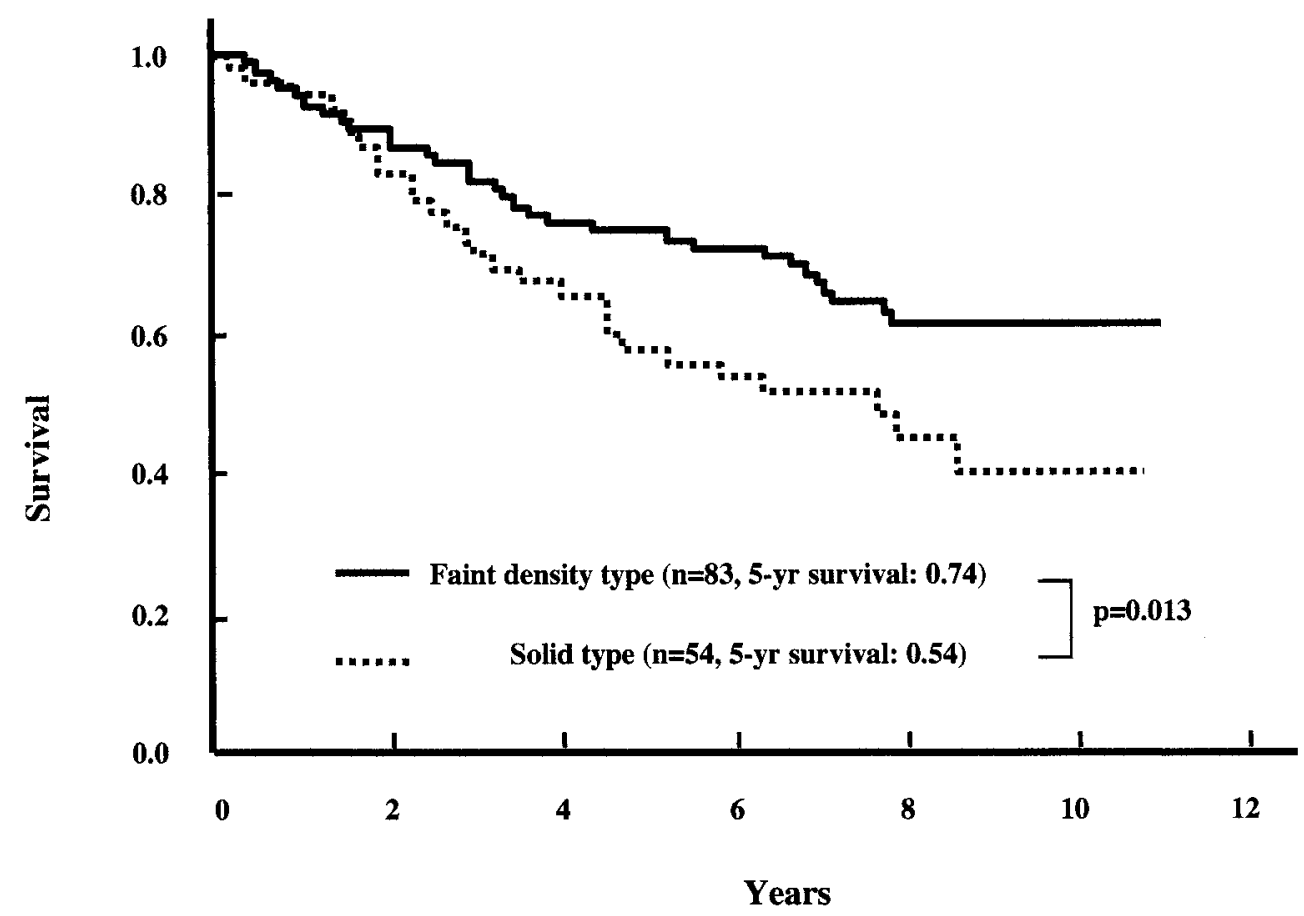

Figure 3. Survival curves of patients with completely resected tumors. The survival of patients with faint density-type CT images was significantly higher than that of patients with solid-type CT images $(P=.013$, log-rank test).

eration. Tumors were completely removed in 137 patients, but 6 had residual tumors: 3 patients had malignant pleural effusion; 1 patient had pleural dissemination; 1 patient had malignant pericardial effusion; and 1 patient had residual tumor at the bronchial stump. CT images were photographed with a window level of $-600 \mathrm{H}$ and window width of $2000 \mathrm{H}$ for lung windows and a level of $10 \mathrm{H}$ and width of $300 \mathrm{H}$ for mediastinal windows. Each image was analyzed with National Institutes of Health imaging software. The areas in the lung and mediastinal windows of the tumors were both measured 3 times. Mean values were used to calculate the tumor's ratio of the area of the mediastinal computed tomographic image to that of the lung computed tomographic image $(\mathrm{CT} \mathrm{M} / \mathrm{L}$ ratio; CT M/L ratio = tumor's area in the mediastinal CT image/tumor's area in the lung CT image $\times 100 \%$ ). All patients were classified into one of two groups: the solid-type tumor group (CT $\mathrm{M} / \mathrm{L}$ ratio $\geq 50 \%$ ) and the faint density-type tumor group (CT M/L ratio <50\%). ${ }^{6}$ Examples of $\mathrm{CT}$ images of the two groups are shown in Figures 1 and 2. Tumors with ground-glass opacity $(\mathrm{GGO})^{7}$ in lung $\mathrm{CT}$ images were defined as GGO positive. The medical records of all patients were reviewed for clinical and pathologic characteristics, including age, sex, tumor size, lymph node involvement, pathologic stage, and histologic grade. The length of survival was defined as the period from the day of the operation to the last day of follow-up or the date of death from any cause. The survivals were calculated by means of the Kaplan-Meier method, and statistical analysis was performed by means of the log-rank test. The $\chi^{2}$ test or Fisher exact test was used to compare several clinical or pathologic factors. The Cox proportional hazards model was applied for multivariate analysis by using version 5.0 of the StatView software package (SAS Institute Inc, Cary, NC).

\section{Results}

Patient characteristics are summarized in Table 1. There were 58 patients with solid-type tumors and 85 patients with faint density-type tumors. There was no significant difference in age distribution and sex between the two groups. Of 58 patients with solid-type tumors, only 8 had tumors with maximum diameters of $20 \mathrm{~mm}$ or less, whereas there were 30 patients in the total of 85 with faint density-type tumors $(P=.008)$. Thirty-seven patients with solid-type tumors proved to have no nodal involvement, 2 patients had N1 disease, and 19 had N2 disease pathologically. In the faint density group the numbers of patients with no nodal involvement, N1 disease, and N2 disease were 68, 6, and 11, respectively. The number of patients with nodal involvement was significantly higher in the solid-type tumor group than that among the patients with faint density-type tumors $(P=.032)$. We also compared histologic grade between the two groups but found no statistical difference $(P=.056)$. In the lung CT images of patients with faint density-type tumors, 45 were proved to have GGO, and 40 were proved not to have GGO. In the solid-type tumor group, on the 
other hand, only 7 patients had GGO, and 41 did not $(P<$ $.0001)$.

The 5-year survival of patients with faint density-type images whose tumors were completely resected was $74.1 \%$, which was significantly higher than that of patients with solid-type CT images (5-year survival, 54.2\%; $P=.013$; Figure 3). To exclude the influence of lymph node metastasis, we also compared the survivals of the patients with stage IA disease between the two groups. The 5-year survival of patients with stage IA disease with faint densitytype images was $86.1 \%$, whereas it was $74.5 \%$ in the other group, which showed a significant difference $(P=.047$, Figure 4). The curve of patients with solid-type images without GGO showed the worst survival. However, there was no significant difference among patients with faint density-type tumors with GGO, faint density-type tumors without GGO, and solid-type tumors with GGO (Figure 5). A significant difference existed between the prognosis of the solid-type tumor group without GGO and that of the group consisting of faint density-type and solid-type tumors with $\mathrm{GGO}(P=.005$, Figure 6$)$.

The multivariate analysis (Table 2) showed the CT M/L ratio to be a significant prognostic factor $(P=.03$; hazard ratio, 0.48; 95\% confidence interval, 0.24-0.95). The $P$ value of the CT M/L ratio was the second highest after that of the $\mathrm{N}$ factor and was the same as that of tumor size.

\section{Discussion}

Several factors, such as lymph node metastasis, histologic subtype (as proposed by Noguchi and colleagues ${ }^{8}$ ), and size of central fibrosis, have been proved to be of prognostic importance, but few of them can be evaluated preoperatively. ${ }^{1-5,9}$ In this study we found that the 5-year survivals of patients with faint density-type CT images were significantly better than those of patients with solid-type CT images (Figure 3). There was also a significant difference between the two groups, even if the cases were limited to stage IA disease (Figure 4). Furthermore, patients with solid-type CT images who had no GGO component had the worst 5-year survival (Figures 5 and 6). The multivariate analysis revealed the prognostic influence of the CT M/L ratio on survival $(P=.029$; relative risk, 0.48 ; Table 2$)$, with its effect being the second highest after that of the $\mathrm{N}$ factor. All these findings strongly suggest that the CT M/L ratio might be a possible prognostic factor of peripheral lung adenocarcinomas $30 \mathrm{~mm}$ or less in size that can be evaluated preoperatively.

The reason why patients with small peripheral lung adenocarcinomas with solid-type CT images have a poor prognosis is still unclear. Isobe and coworkers ${ }^{10}$ reported that small peripheral lung lesions that have high CT M/L ratios (the solid type) often appear as poorly differentiated adenocarcinomas. On the other hand, tumors with $0 \% \mathrm{CT}$ $\mathrm{M} / \mathrm{L}$ ratios often appear as well-differentiated adenocarci-
TABLE 1. Characteristics and CT images of patients with adenocarcinoma of the lung (tumor diameter $\leq \mathbf{3 0} \mathrm{mm}, \mathbf{n}=$ 143)

\begin{tabular}{|c|c|c|c|}
\hline & \multirow[b]{2}{*}{$\begin{array}{c}\text { No. of } \\
\text { patients }\end{array}$} & \multicolumn{2}{|c|}{ CT findings } \\
\hline & & $\begin{array}{l}\text { Solid } \\
\text { type }^{*}\end{array}$ & Faint density type \\
\hline Total & 143 & 58 & 85 \\
\hline \multicolumn{4}{|l|}{ Sex } \\
\hline Male & 65 & 28 & 37 \\
\hline Female & 78 & 30 & 48 \\
\hline Age (y) & $62.6 \pm 9.9$ & $62.5 \pm 9.9$ & $62.8 \pm 9.9$ \\
\hline \multicolumn{4}{|l|}{ Tumor size } \\
\hline$\leq 20 \mathrm{~mm}$ & 38 & 8 & 30 \\
\hline$>20 \mathrm{~mm}$ & 105 & 50 & 55 \\
\hline \multicolumn{4}{|c|}{ Nodal involvement } \\
\hline NO & 105 & 37 & 68 \\
\hline N1 & 8 & 2 & 6 \\
\hline N2 & 30 & 19 & 11 \\
\hline \multicolumn{4}{|l|}{ p Stage } \\
\hline Stage I & 101 & 35 & 66 \\
\hline Stage II & 8 & 2 & 6 \\
\hline Stage III & 33 & 20 & 13 \\
\hline Stage IV & 1 & 1 & 0 \\
\hline \multicolumn{4}{|c|}{ Histologic grade } \\
\hline Well & 52 & 18 & 34 \\
\hline Moderate & 73 & 36 & 37 \\
\hline Poor & 18 & 4 & 14 \\
\hline \multicolumn{4}{|l|}{ GGO } \\
\hline+ & 52 & 7 & 45 \\
\hline- & 91 & 51 & 40 \\
\hline
\end{tabular}

*Solid type: tumor's area in mediastinal window/tumor's are in lung window $\geq 50 \%$.

†Faint density type: tumor's area in mediastinal window/tumor's area in lung window $<50 \%$.

nomas. Andoh and associates ${ }^{6}$ studied the roentgenopathologic correlation of 12 patients with small peripheral adenocarcinomas measuring $15 \mathrm{~mm}$ or less in greatest dimension and found that all patients $(\mathrm{n}=4)$ who had a faint density type of thin-section CT images were classified as having histologic subtypes A and B (Noguchi classification). ${ }^{8}$ Among the 8 patients of the solid-type tumor group, there were also 3 patients classified as having subtypes A and $\mathrm{B}$ in whom the alveolar spaces were filled with mucus. Therefore, it cannot be demonstrated that the change of the tumor's area in the thin-section CT image correlates with the histologic subtype of Noguchi's classification. However, our study demonstrated that CT image comparison between the mediastinal and lung CT images is possibly of prognostic value in patients with peripheral lung adenocarcinoma. Because our study included patients whose tumors were larger than $15 \mathrm{~mm}$, the biologic behavior and clinical values of the CT images are different from those in the previous studies, which dealt with only small nodules.

It is generally thought that most adenocarcinomas develop either de novo or through the stage of atypical adeno- 


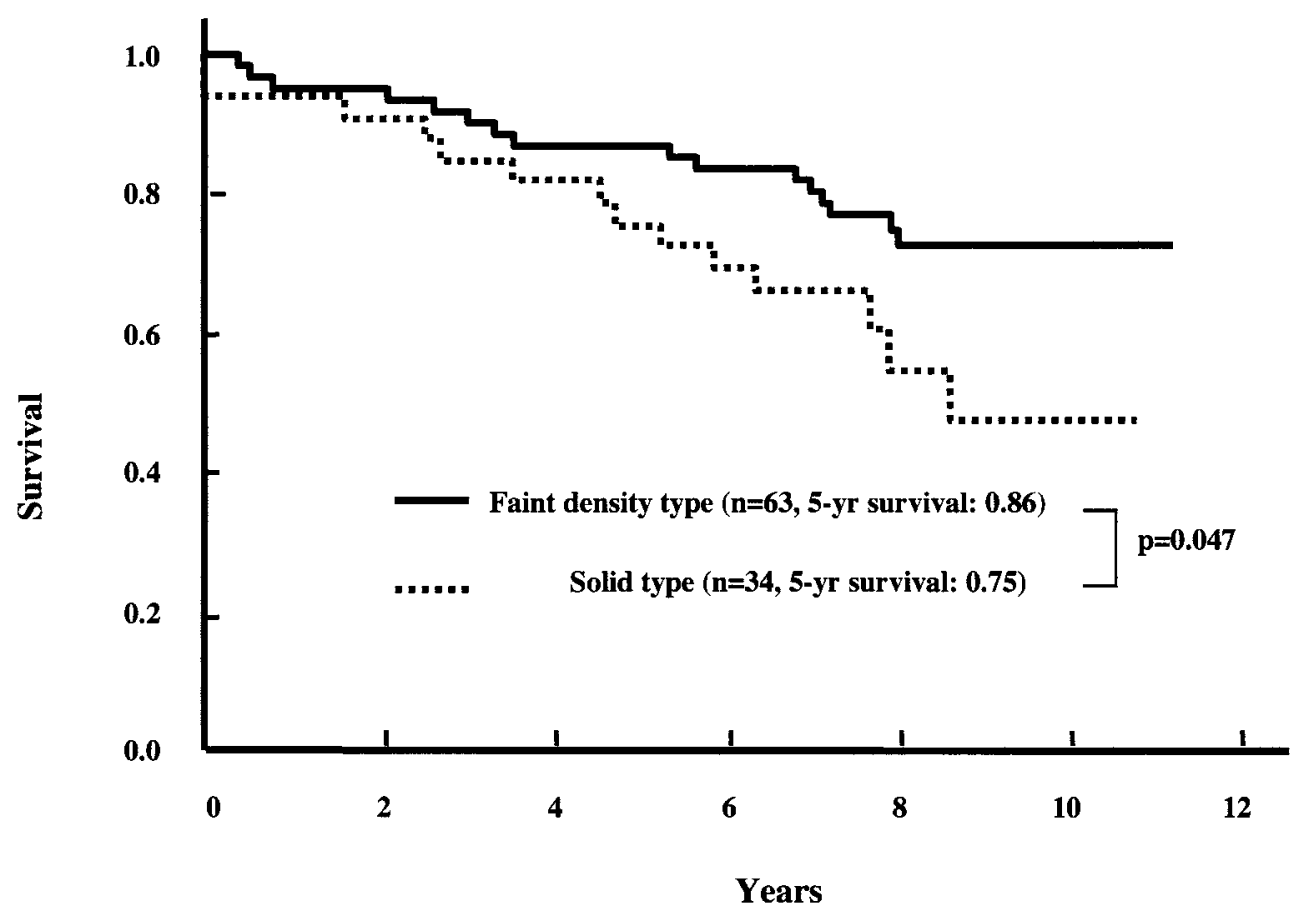

Figure 4. Survival curves of patients with stage IA disease. The survival of patients with faint density-type CT images was significantly higher than that of patients with solid-type CT images $(P=.047$, log-rank test).

TABLE 2. Multivariate analyses of prognostic factors

\begin{tabular}{|c|c|c|c|c|}
\hline Variables & $\begin{array}{l}\text { Estimated } \\
\text { coefficient }\end{array}$ & SE & $P$ value & $\begin{array}{c}\text { Relative risk } \\
(95 \% \mathrm{CI})\end{array}$ \\
\hline Nodal involvement (N0 vs N1+2) & -2.27 & 0.35 & $<.0001$ & $0.10(0.05-0.20)$ \\
\hline CT $\mathrm{M} / \mathrm{L}$ ratio* $(<50 \%$ vs $\geq 50 \%)$ & -0.73 & 0.34 & .03 & $0.48(0.24-0.95)$ \\
\hline Tumor size ( $\leq 20 \mathrm{~mm}$ vs $>20 \mathrm{~mm})$ & -0.64 & 0.39 & .03 & $0.43(0.20-0.93)$ \\
\hline Sex (male vs female) & -0.55 & 0.35 & .12 & $0.58(0.29-1.16)$ \\
\hline Histologic grade (well vs moderate + poor) & -0.44 & 0.43 & .30 & $0.64(0.28-1.49)$ \\
\hline Age $(<60$ y vs $\geq 60$ y) & -0.04 & 0.34 & .91 & $0.96(0.49-1.89)$ \\
\hline
\end{tabular}

$\mathrm{Cl}$, Confidence interval.

${ }^{*} \mathrm{CT} \mathrm{M} / \mathrm{L}$ ratio: tumor's area in the mediastinal CT image/tumor's area in the lung $\mathrm{CT}$ image $\times 100 \%$.

matous hyperplasia. ${ }^{11}$ Several investigators have reported that GGO demonstrated by means of high-resolution computed tomography might be due to bronchioloalveolar adenoma of the lung or bronchioloalveolar carcinoma. ${ }^{7,12,13}$ In the study by Jang and associates, ${ }^{14}$ follow-up CT scans in 3 of 4 patients with bronchioloalveolar carcinoma showed replacement of the GGO by means of consolidation, leading to speculation that the areas of GGO might represent an early stage of bronchioloalveolar carcinoma. Kodama and coworkers ${ }^{15}$ proved that the bronchioloalveolar carcinoma area was well correlated with the GGO area on high-resolution computed tomography. He also showed that the 3-year relapse-free survivals of patients with GGO of greater than $50 \%$ were significantly better than those of patients with GGO of less than 50\%. All of these findings suggest that GGO is well correlated with the development and malignant progression of some adenocarcinomas of the lung. It was also supported by our finding that tumors of the solid-type CT image group without GGO had the worst prognosis (Figures 5 and 6).

In conclusion, our results suggest that the $\mathrm{CT} \mathrm{M} / \mathrm{L}$ ratio is a possible prognostic factor of small peripheral lung adenocarcinoma of $30 \mathrm{~mm}$ or less, which can be evaluated preoperatively. The multivariate analysis showed the prognostic influence of the CT M/L ratio on survival to be the second highest after that of the $\mathrm{N}$ factor. We believe that 


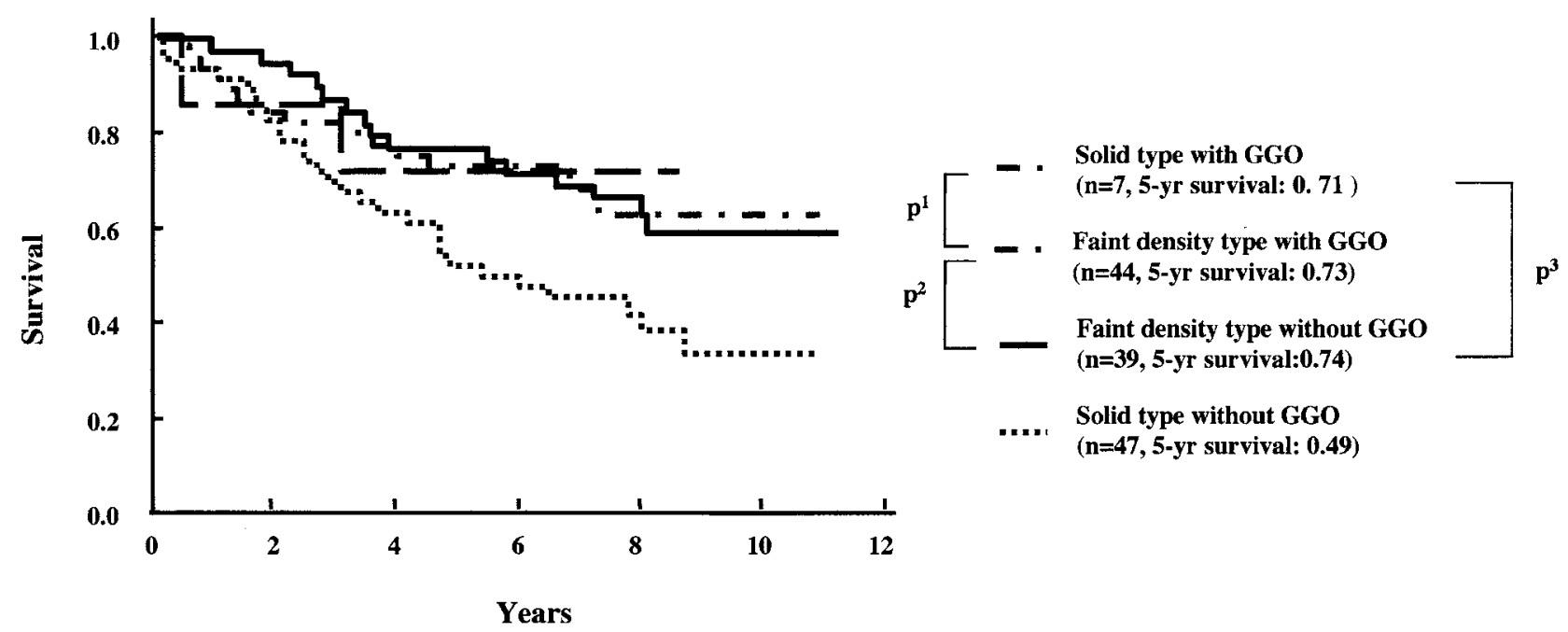

Figure 5. Survival curves on the basis of CT images (with or without GGO in both types). There were no significant differences among patients with faint density-type tumors with GGO, solid-type tumors with GGO, and faint density-type tumors without $\mathrm{GGO}\left(P^{1}=.89, P^{2}=.99, P^{3}=.88\right)$.

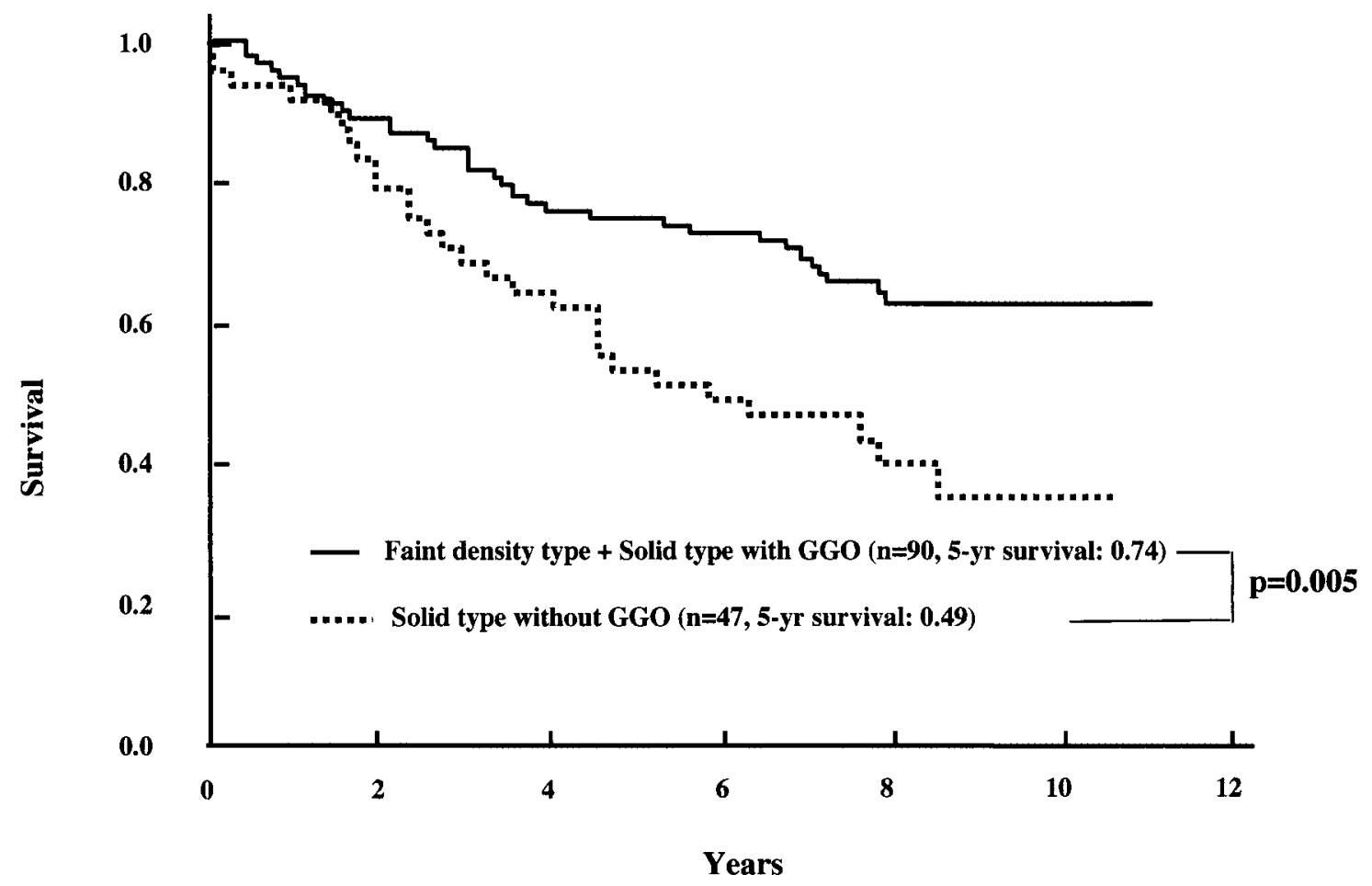

Figure 6. Survival curves of patients with solid-type tumors without GGO and of patients with other types of CT images. There was a significant difference between the two groups (solid-type tumors without GGO vs faint density-type tumors and solid-type tumors with GGO: $P=.005)$. 
these findings hold promise for a new prognostic factor in the pretreatment period.

\section{References}

1. Suzuki K, Nagai K, Yoshida J, Nishimura M, Takahashi K, Nishiwaki Y. Conventional clinicopathologic prognostic factors in surgically resected non-small cell lung carcinoma. Cancer. 1999;86:1976-84.

2. Lima C, Matsui K, Kitagawa M, Mizushima Y, Noto H, Miwa A. Analysis of prognostic factors in patients with resected peripheral T1 adenocarcinoma of the lung. Pathol Res Pract. 1993;189:1149-53.

3. Yokose T, Suzuki K, Nagai K, Nishiwaki Y,Sasaki S, Ochiai A. Favorable and unfavorable morphological prognostic factors in peripheral adenocarcinoma of the lung $3 \mathrm{~cm}$ or less in diameter. Lung Cancer. 2000;29:179-88.

4. Hwang J, Lee K, Han J, Kim TS, Lee JY, Kim J. Papillary adenocarcinoma of the lung: radiologic and pathologic findings. J Comput Assist Tomogr. 1999;23:114-7.

5. Higashiyama M, Kodama K, Yokouchi H, Takami K, Mano M, Kido $\mathrm{S}$, et al. Prognostic value of bronchiolo-alveolar carcinoma component of small lung adenocarcionoma. Ann Thorac Surg. 1999;68:2069-73.

6. Andoh M, Seike M, Yoshimura A, Gemma A, Shibuya M, Kudoh S, et al. Retrospective studies on the diagnosis of peripheral small lung adenocarcinoma [in Japanese with English abstract]. Jpn Soc Bronchology. 1999;21:381-6.

7. Collins J, Stern E. Ground-glass opacity at CT: the ABCs. AJR Am J Roentgenol. 1997;169:355-67.
8. Noguchi M, Morikawa A, Kawasaki M, Matsuno Y, Yamada T, Hirohashi S, et al. Small adenocarcinoma of the lung: histologic characteristics and prognosis. Cancer. 1995;75:2844-52.

9. Suzuki K, Yokose T, Yoshida J, Nishimura M, Takahashi K, Nagai K, et al. Prognostic significance of the size of central fibrosis in peripheral adenocarcinoma of the lung. Ann Thorac Surg. 2000;69:893-7.

10. Isobe T, Yamada K, Oshita F, Nomura I, Noda K, Tajiri M, et al. CT Analysis of resected lung carcinoma less than $1.5 \mathrm{~cm}$ in diameter [in Japanese with English abstract]. Jpn J Lung Cancer. 1995;35:891-9.

11. Shimosato Y, Noguchi M, Matsuno Y. Adenocarcinoma of the lung: its development and malignant progression. Lung Cancer. 1993;9:99108 .

12. Kushihashi T, Munechika H, Ri K, Kubota H, Ukisu R, Satoh S, et al. Bronchioloalveolar adenoma of the lung: CT-pathologic correlation. Radiology. 1994;193:789-93.

13. Kuriyama K, Seto M, Kasugai T, Higashiyama M, Kido S, Sawai Y, et al. Ground-glass opacity on thin-section CT: value in differentiating subtypes of adenocarcinoma of the lung. AJR Am J Roentgenol. 1999;173:465-9.

14. Jang HJ, Lee KS, Kwon OJ. Rhee CH, Shim YM, Han J. Bronchioloalveolar carcinoma: focal area of ground-glass attenuation at thinsection CT as an early sign. Radiology. 1996;199:485-8.

15. Kodama K, Higashiyama M, Yokouchi H, Takami K, Kuriyama K, Mano M, et al. Prognostic value of ground-glass opacity found in small lung adenocarcinoma on high-resolution CT scanning. Lung Cancer. 2001;33:17-25.

\section{Targeted}

The Journal of Thoracic and Cardiovascular Surgery gives you two tables of contents. The condensed table of contents tells you at a glance what topics and authors are presented each month. The expanded table of contents gives you a brief abstract of each article. You select only those articles of most interest to you for further reading. 